\title{
Microcirculation in Pregnancy
}

\author{
I. ABDO ${ }^{1,2}$, R. B. GEORGE ${ }^{1,3}$, M. FARRAG ${ }^{4}$, V. CERNY ${ }^{1,2}$, C. LEHMANN $^{1}$ \\ ${ }^{1}$ Department of Anesthesiology, Pain Management, and Perioperative Medicine, Dalhousie \\ University, Halifax, Canada, ${ }^{2}$ Department of Anesthesiology and Intensive Care Medicine, Charles \\ University in Prague, Faculty of Medicine Hradec Kralove, Czech Republic, ${ }^{3}$ Department of \\ Women's \& Obstetric Anesthesia, IWK Health Centre, Halifax, Canada, ${ }^{4}$ Department of \\ Gynecology and Obstetrics, Hospital of Chrudim, Chrudim, Czech Republic
}

Received January 15, 2013

Accepted January 31, 2014

On-line April 3, 2014

\section{Summary}

The microcirculation, like all physiological systems undergoes modifications during the course of pregnancy. These changes aid the adaption to the new anatomical and physiological environment of pregnancy and ensure adequate oxygen supply to the fetus. Even though the microcirculation is believed to be involved in major pregnancy related pathologies, it remains poorly understood. The availability of safe and non-interventional technologies enabling scientists to study the intact microcirculation of the pregnant patient will hopefully expand our understanding. In this article we review the physiological changes occurring in the microcirculation during pregnancy and the role of the microcirculation in gestational related pathologies. We will also describe the available techniques for the measurement and evaluation of the microcirculation. Lastly we will highlight the possible fields in which these techniques could be utilized to help provide a clearer view of the microcirculation in the pregnant woman.

\section{Key words}

Pregnancy - Microcirculation - Preeclampsia - Diabetes • Gestational

\section{Corresponding author}

V. Cerny, Department of Anesthesiology and Intensive Care, Faculty of Medicine in Hradec Kralove, University Hospital Hradec Kralove, Charles University in Prague, 50005 Hradec Kralove, Czech Republic. E-mail: cernyvla1960@gmail.com

\section{Introduction}

Pregnancy remains one of nature's great miracles and an example of how the human body and its vital systems indulge in a symphony orchestrated by profound change. The hormonal milieu, the mechanical effects of an enlarging uterus, and the increased metabolic demand of the fetal placental unit result in a cascade of specific alterations and modifications. The unique physiology of pregnancy allows maternal adaptation to meet the demands of the growing fetus, supporting placental unit, and ultimately to facilitate labor and delivery.

The microcirculation plays a crucial role in the interaction between blood and tissue both in the physiological and pathophysiological states ensuring fetal and maternal well-being (Ohlmann et al. 2001). Though crucially important, surprisingly little is known of the impact of physiological changes in the microcirculation of the pregnant woman. Despite this lack of information, several hypotheses consider microcirculatory dysfunction having a role in gestational pathology as in preeclampsia and gestational diabetes mellitus.

In this paper we intend to shed light on the physiological changes occurring in the microcirculation during pregnancy; review the role of the microcirculation in gestational related pathologies; and demonstrate the available techniques for the measurements and evaluation of the microcirculation. Lastly we will highlight the possible fields in which these techniques could be utilized 
to help provide a clearer view of the microcirculation in the pregnant woman.

\section{Search methods}

For our review we searched MEDLINE/PubMed (1976 to March 2011) and Embase (1970 to March 2011). Due to the scarce literature about the subject and the broad spectrum of our search, we used key words either in a single or combined manner to filter and effectively narrow our results, these included pregnancy, microcirculation, preeclampsia, vascular dysfunction, gestational diabetes. Our search resulted yield 8,939 articles. After thorough evaluation of the abstracts, we excluded articles with little relevance or plagiarism. We included 83 articles, which were reviewed in full text and included in our review.

\section{Physiological microcirculatory changes during pregnancy}

The physiological modifications occurring during pregnancy affect nearly all organs. The cardiovascular system undergoes changes early in pregnancy when the osmotic thresholds for thirst and antidiuretic hormone secretion are reset to lower levels that allow for the volume expansion of pregnancy. Based on the physiological changes in the cardiovascular system and hemorheological changes ranging from an increase in cardiac output, hemodilution, decrease in peripheral vascular resistance and decreased hematocrit it is assumed that the microvascular flow in the maternal peripheral tissue would increase. However until now little is known about the physiological changes in the maternal microcirculation. This is partly due to limited technologies that allow us to study the intact peripheral microcirculatory system in the pregnant patient.

\section{Pregnant microcirculation and co-existing factors}

It is important to note that the changes in the microcirculation could be further altered by nonphysiological factors, such as obesity, smoking and advanced age. These factors appear to be more dominant in developed countries.

\section{Activity}

Exercise on a daily basis improves the cardiovascular system augmenting blood flow to exercising organs (Huonker et al. 1996). Kvernmo et al. (1998) used iontophoresis to compare endothelium dependent vasoreactivity in long-distance runners and healthy controls. They showed that endotheliumdependent vasoreactivity was better in long distance runners at rest but that the difference was abolished after an exercise test at $80 \%$ of their maximal oxygen uptake. They concluded that exercise had a beneficial effect on the endothelium-dependent vasoreactivity of controls.

\section{Obesity}

Human obesity is an increasingly common condition among both sexes, with an estimated prevalence of 4-28\% among European men and 6-37\% among European women (Berghofer et al. 2008). The prevalence of obesity is also increasing in women of reproductive age and currently it is estimated that more than one in five pregnant women are obese (Heslehurst et al. 2007).

Microvascular abnormalities are well presented in the obese and are secondary to either endothelial dysfunction (Steinberg et al. 1996) or structural impairments in the microvasculature (Van Guilder et al. 2008). Even though obesity can be associated with other conditions that are related to endothelial dysfunction such as hypertension, hypercholesterolemia and hyperglycemia, this endothelial dysfunction can be seen in obese patients without the presence of these conditions. Therefore, obesity by itself could be a primary cause of microvascular dysfunction. Fat distribution plays an important role in the degree of endothelial dysfunction (Hashimoto et al. 1998) thus waist/hip ratio, a determinant of abdominal obesity, is a better marker of endothelial dysfunction than body mass index by itself (Villela et al. 2006). Gavin et al. (2006) demonstrated a decreasing capillary density in skeletal muscle of obese subjects when compared to lean subjects. Furthermore excess of adipose tissue is associated with an increased production of inflammatory cytokines such as tumor necrosis factor-alpha (TNF- $\alpha)$, producing a chronic vascular inflammatory state (Fain et al. 2007).

\section{Smoking}

Cigarette smoking constitutes a well-established risk factor for stroke, coronary heart disease, and occlusive peripheral vascular disease, and thus represents a main cause of death worldwide. Currently, efforts are being made to clarify the effects of tobacco smoke on the 
microcirculation. It is accepted that the presence of endothelial dysfunction is an early marker of vascular injury, predisposing to the development of atherosclerotic lesions. Scardina (2005) investigated the lingual mucosa in cigar smokers, using computerized video capillaroscopy. They investigated the visibility, course, tortuosity, and any images characteristic of capillary loops, as well as the possible presence of microhemorrhages, the average caliber of the capillary loops, and the number of capillary loops visible per square millimeter. In smokers, capillary loops had a smaller caliber and there were a higher number of detectable capillary loops thus showing a correlation between capillary tortuosity and cigar smoking. This showed that chronic smoking induces significant changes in lingual capillary morphology, caliber, and number. Siafaka et al. (2007) looked at the acute effects of smoking using near-infrared spectroscopy, combined with the arterial occlusion technique, showing endothelial dysfunction being recordable even before the subject finished smoking the cigarette. Edvinsson et al. (2008) used Laser Doppler Flowmetry (LDF) to measure the cutaneous forearm blood flow in smokers and nonsmokers. The vasodilatory response to the iontophorectic administration of acetylcholine (ACh), acting via an endothelial mechanism, and sodium nitroprusside (SNP), and acting via a smooth muscle mechanism were studied. There was a reduced peripheral microvascular response to both endothelial and smooth muscle cell stimulation in smokers when compared to non-smokers, suggesting a generalized microvascular vasomotor function.

Age

As women age, the risk of problems in pregnancy increases, including miscarriage, chromosomal abnormalities such as Down syndrome, and other complications such as gestational diabetes, high blood pressure, and bleeding. Moron et al. (1989) showed that women over 40 are at higher risk of experiencing the sudden death of their fetuses than their younger counterparts. Endothelial dysfunction is the earliest marker for age-related abnormalities in vascular function. Tao et al. (2004) and Taddei et al. (1995) have evaluated the effects of aging on arterial elasticity. Endothelial function was evaluated by ACh and SNP to the forearm vessels using iontophoresis and measured the flow using LDF. The studies showed that endothelium vasoreactivity was decreased in the elderly compared with young subjects. There were no differences in endothelium- independent vasoreactivity, possibly due to the reduction in endothelium derived nitric-oxide (Gerhard et al. 1996). Abdo et al. (2012) looked at the changes in the density and flow of the microcirculation in different age groups using SDF (Sidestream Dark Field) imaging. As age increased, there was a linear decrease in both the FCD (functional capillary density) and MFI (microvascular flow index) with the significant changes occurring after the age of 70 .

\section{Pregnancy related pathological conditions}

During pregnancy a small number of women develop pathological conditions that could be lifethreatening for both the mother and the fetus. In this section we review two conditions in which microcirculatory dysfunction might play a role in its etiology or result in complications that persist even after delivery.

\section{Preeclampsia}

Preeclampsia is a multi-system disorder and is estimated to affect $7 \%$ to $10 \%$ of all pregnancies in the United States (August and Lindheimer 1995). Preeclampsia in women is typically characterized by hypertension, proteinuria, and edema, with the hemodynamic disturbances being the most prominent feature. These disturbances commence in early gestation and account for the development of the clinically apparent vasoconstriction and increase in arterial pressure as gestation progresses. Despite being one of the leading causes of maternal death and a major contributor to maternal and perinatal morbidity, the mechanisms responsible for the pathogenesis of preeclampsia have not yet been fully elucidated. Hypertension associated with preeclampsia develops during pregnancy and remits after delivery, implicating the placenta as a central culprit in the disease. An initiating event in preeclampsia has been postulated to be reduced placental perfusion that leads to widespread dysfunction of the maternal vascular endothelium by mechanisms that remain to be defined.

Although the pathophysiology of preeclampsia remains undefined, placental ischemia/hypoxia is widely cited as a key factor (Fisher and Roberts 1999). According to this concept, inadequate trophoblast invasion and remodeling of the uterine spiral arteries during preeclampsia results in a reduction in uteroplacental perfusion (Fisher and Roberts 1999). This reduction in placental oxygenation is thought to enhance 
the synthesis and release of factors such as cytokines (Conrad and Benyo 1997), which induce widespread activation/dysfunction of the maternal endothelium in vessels of the kidney and other organs (Roberts et al. 1991, Rinehart et al. 1999). Several reports suggest an increase in cytokine levels in woman with preeclampsia. Conrad et al. (1998) showed an increase in plasma levels of TNF- $\alpha$ and IL- 6 in women with. In addition, both IL- $1 \beta$ and TNF- $\alpha$ are more highly expressed by the placentas of women with preeclampsia than those from normotensive controls (Wang and Walsh 1996, Ranta et al. 1999). In vitro studies indicate that both TNF- $\alpha$ and IL-1ß induce a variety of structural and functional changes in endothelial cells consistent with cell activation (Cotran and Pober 1990, Pijnenborg et al. 1991). Clinically, preeclampsia is characterized by hypertension, enhanced vascular reactivity to vasoconstrictors, and vasospasm of retinal vessels. All of these changes may be explained by endothelial activation and associated changes in the production of vasoactive factors. Ohlmann et al. (2001) used periungual capillary microscopy, to investigate the changes in peripheral microcirculation during pregnancy focusing on pregnancy induced hypertension. Sixty-seven normotensive pregnant women and 28 women with pregnancy induced hypertension were evaluated. Throughout the prospective study three examinations were performed during pregnancy and one during childbirth. The women who developed pregnancy induced hypertension were registered during the third trimester. Erythrocyte velocity at rest and vascular reactivity of capillaries following a 3-minute ischemia were evaluated. In the course of pregnancy a significant increase of approximately $30 \%$ in erythrocyte velocity could be observed, interpolation to obtain the best strait line result demonstrates that it is a continuous increase. Erythrocyte velocity returns to normal in the course of 14 weeks postpartum.

Due to a physiological vasodilatation during pregnancy, vascular reaction to ischemic stress significantly decreases. Examinations on women with pregnancy induced hypertension not only showed a significant reduction of microcirculation under resting conditions but also a different pattern of reaction to ischemic stress. Erythrocyte velocity under resting conditions lies $36 \%$ below normal values. Furthermore the distinctly shortened hyperemic period indicates increased sensitivity to vasoconstrictive substances in women with preeclampsia (Ohlmann et al. 2001).

Although recent studies support a role for cytokines and other factors such as lipid peroxides and reactive oxygen intermediates as potential mediators of endothelial dysfunction, identification of the $\operatorname{link}(\mathrm{s})$ between placental ischemia and maternal endothelial and vascular abnormalities remains an important area of investigation. Other markers of endothelial dysfunction have been reported in woman with preeclampsia, which further supports the suggestion that it is an endothelial cell disorder. An imbalance of anticoagulation and procoagulation factors is found in preeclampsia, showing an increase in the proteins of the coagulation cascade. Circulating levels of fibronectin are significantly increased in preeclampsia with measurable increases observed as early as 20 weeks of pregnancy (Sud et al. 1999). Plasma thrombomodulin is also significantly elevated (Bontis et al. 1995, Shaamash et al. 2000), with elevations detected as early as 24 weeks of pregnancy (Boffa et al. 1998). Furthermore, an imbalance in endothelial-derived vasodilator and vasoconstrictor factors is evident in preeclampsia. The plasma concentration of prostacyclin, a potent vasodilator and inhibitor of platelet aggregation is significantly decreased (Gerretsen et al. 1981, Mastrogiannis et al. 1991), while thromboxane is increased in severe preeclampsia, shifting the prostacyclin/thromboxane ratio towards vasoconstriction (Gerretsen et al. 1981). Decreased levels of prostacyclin can be detected as early as 16 weeks of gestation in preeclamptic woman (Mastrogiannis et al. 1991). Such early changes in the endothelial dysfunction deepens the belief that endothelial dysfunction could be the possible cause of preeclampsia rather than the result. Ramsay et al. (2003) used LDF imaging proving that endothelial dysfunction persisted in a group of women 15-25 years following a pregnancy complicated by preeclampsia. They further drew a possible link between preeclampsia and maternal coronary heart disease and concluded that pregnancies complicated by preeclampsia may identify women at risk of vascular disease in later life. This may provide the opportunity for lifestyle and risk factor modification to alter the risk. Ramsay et al. (2003) and Khan et al. (2005) examined endothelial function sequentially at different gestations before development of the clinical syndrome and after delivery. Using the LDF, they measured endothelial function at 22, 26 , and 34 weeks gestation and 6 weeks postpartum in women at increased risk for preeclampsia. They chose uterine arterial notching as a means of identifying a cohort of women at increased risk of preeclampsia (Mires et al. 1998). The authors have shown that skin 
microvascular responses are enhanced in women in whom preeclampsia develops. This enhancement in vascular function is over and above that seen in normal pregnancy and possibly results from a compensatory response of the microvasculature to decreased nitric oxide production. Importantly, these changes within the microcirculation preceded the onset of clinical disease by weeks or months (Mires et al. 1998). Early assessment of vascular function in women at increased risk for preeclampsia might help in the identification of potentially vulnerable patients and enable therapeutic strategies to be targeted to this potentially dangerous condition.

\section{Gestational diabetes mellitus}

Gestational diabetes mellitus (GDM) is defined as carbohydrate intolerance with onset or first recognition during pregnancy (Metzger 1991) and is associated with several perinatal complications (Jovanovic and Pettitt 2001). Women with GDM and their offspring are also at increased risk of developing diabetes later in life (Jovanovic and Pettitt 2001). It affects up to $14 \%$ of the pregnant population, approximately 135,000 women per year in the United States. GDM has many known systemic effects that have a major influence on the mother and her developing fetus. Spontaneous abortions increase significantly in the diabetic patient (Combs and Kitzmiller 1996). It is possible that poor glycemic control in the first trimester leads to anomalies in the developing embryo that lead to loss of the pregnancy. Preterm labor is also increased by $25 \%$. This is due to greater uterine volume, hypertension, and frequent urinary tract infection seen in women with GDM, as well as vascular compromise associated with diabetic changes at the microvascular level. Microvascular changes related to non-pregnant diabetes mellitus are well documented in the literature, but the degree of change in gestational diabetes remains incompletely understood. $\mathrm{Hu}$ et al. (1998) assessed macro- and microvascular function in non-pregnant woman without signs of diabetes two to four years after a pregnancy complicated with GDM. The microvascular perfusion in the skin of the hand and foot was recorded by the LDF. At the microcirculatory level they demonstrated a diminished vasodilatory response in the skin microvessels of the hand and foot, indicating endothelial dysfunction ( $\mathrm{Hu}$ et al. 1998). Interestingly, the degree of reduced skin vasodilatory microvascular response in gestational diabetics was more or less the same in the hand and the foot, whereas clinical vascular complications in the skin associated with non-insulin dependent diabetes mellitus almost exclusively involve the feet. Hanemann et al. (2002) further confirmed these vascular changes in a separate study that looked mainly at the skin microvascular changes in the forearm only rather than the foot and the hand. Both studies did not assess the vascular functions during pregnancy, thus it is unknown whether the alterations of the vascular functions existed in these women during pregnancy (Hu et al. 1998, Hanemann et al. 2002).

At the molecular level, Bo et al. (2007) looked at endothelial dysfunction and inflammatory markers in 82 non pregnant woman with previous GDM and 113 control women without previous GDM, 6.5 years after delivery. The markers included where C-reactive protein (CRP), interleukin-6 (IL-6), E-selectin, intercellular adhesion molecule-1 (ICAM-1), and vascular adhesion molecule-1 (VCAM-1) (Bo et al. 2007). Post GDM woman, regardless of their current metabolic status, showed significantly higher values of E-selectin and ICAM-1 than controls, not associated with the BMI. However, increases in IL-6 and CRP values correlated with higher BMI. They concluded that women with a GDM history, although currently free from metabolic abnormalities, appear to be at increased risk of endothelial impairment and vascular diseases in later life and may require counseling and appropriate advice on lifestyle.

As GDM plays a role in systemic endothelial dysfunction systemically, it also seems to play a role at the vascular level in the placenta. Placentas from diabetic pregnancies show an increased incidence of vascular pathological changes. Such changes can affect the arteries and veins and are most frequently observed in stem villi of different sizes, corresponding to peripheral vessels (Daskalakis et al. 2008). These lesions affect the fetoplacental circulation (Benirschke and Kaufmann 1995).

\section{Technologies for evaluating the microcirculation}

Blood flow in the skin microcirculation is composed of the nutritional capillaries and thermoregulatory arteriovenous (AV) shunts. The proportional contribution of these two sources is different in glabrous and nonglabrous skin. Twenty-five percent of glabrous skin blood flow comes from nutritional capillaries and $75 \%$ from AV shunts, and it is therefore 
subject to wide fluctuations (Midttun et al. 1997). Nonglabrous skin does not possess AV shunts, and blood flow is composed almost completely of nutritional capillaries. Structural differences in skin blood vessel architecture account for variations in blood flow between glabrous and nonglabrous skin. Saad et al. (2001) found that skin blood flow decreased significantly in response to isometric exercise in glabrous, but not nonglabrous skin. These results suggest that AV shunts in glabrous skin cause a more sustained vasoconstrictor tone, which may increase the risk for the sequelae of PVD in this region.

The microcirculation was first evaluated in the coronary circulation, where it was shown that microcirculatory dysfunction was associated with an increased risk of coronary artery disease. Dilatation of the coronary microvasculature can be assessed by measuring coronary blood flow with a Doppler velocity catheter. This invasive technique carries the risks associated with angiography and is not well suited to multiple measurements over time. This led investigators to evaluate other arterial beds because endothelial dysfunction was thought to be a global process. Flowmediated dilatation of the brachial artery (macrocirculation) due to occlusive hyperemia has been shown to have a close association with coronary vasoreactivity (Anderson et al. 1995). Flow-mediated dilatation does not specifically evaluate the endresistance arteries of the microcirculation, requires an ultrasound technician, and can have up to $25 \%$ day-today variability (Verma et al. 2003). The importance of small-vessel resistance for ulcer formation led to the development of both invasive and noninvasive techniques that could reliably quantify microcirculatory function.

\section{Transcutaneous oxygen tension}

Transcutaneous oxygen tension $\left(\mathrm{TCpo}_{2}\right)$ has been an integral part of the noninvasive assessment of microcirculatory blood flow since the 1970s. $\mathrm{TCpo}_{2}$ quantifies oxygen molecules transferred to the skin microcirculation after heating it with a transducer to more than $40{ }^{\circ} \mathrm{C}$. $\mathrm{TCpo}_{2}$ is limited because it is time consuming and does not assess all ischemic regions of the skin unless the probe is specifically placed on the tissue of interest.

\section{Pulp skin blood flow}

The pulp skin of the toes has a high incidence of ulcer formation in atherosclerotic vascular disease because of its distal location, and this has led researchers to examine its microcirculation. This can be accomplished using LDF with heat and/or radioisotope washout methods.

LDF scans superficial tissue blood perfusion without physical contact, dyes, or tracer elements, thus minimizing the influence on perfusion and the risk of contamination, infection, or discomfort to the patient. Blood flow is measured as the flux of red blood cells through both the subpapillary vascular bed, which contains AV shunts, and the nutritional capillaries. It is simple to use and can be performed over any area of skin in a minimal amount of time.

To distinguish between the nutritional capillaries and AV shunts in glabrous skin, researchers have used a combination of heat and xenon washout methods (Midttun et al. 1999). Heat washout determines the total microcirculatory blood flow in glabrous skin. A thermostatically controlled electrode is placed on the pulp skin of a finger or toe and is heated $2-10^{\circ} \mathrm{C}$ above normal skin temperature. When the temperature stabilizes, the electrode is turned off, and temperature is measured until it returns to baseline. Skin blood flow is calculated as the slope of the change in temperature versus time.

Radioisotope washout uses xenon 133 (133Xe) to measure the blood flow in capillaries. 133Xe is specific to the nutritional capillaries because of its low diffusion coefficient compared with heat. By subtracting the flow in the 133Xe washout method from that of the heat washout method, one can determine the contribution of blood flow from AV shunts in glabrous skin.

\section{Vasoreactivity}

Evaluation of vasoreactivity is accomplished by comparing blood flow in response to a vasodilator with that in the resting state. The most commonly used vasodilators are acetylcholine (endothelium-dependent) and sodium nitroprusside (endothelium-independent).

Iontophoresis is a noninvasive method that delivers these vasoactive medications subdermally by using an electric potential difference. Microcirculatory flow can be measured with either laser Doppler fluxmetry or single-point laser probes. Vasoreactivity is calculated as the difference between the flow before and after iontophoresis.

Laser Doppler fluxmetry is fast and simple, has small coefficients of variation, and evaluates only nutritional capillary blood flow when performed on nonglabrous skin. Single-point laser probes can be used 
to distinguish the direct and indirect (nerve axon reflex) endothelium-dependent response to acetylcholine.

\section{Capillaroscopy}

Basic light microscopy can be used to study skin capillaries in vivo, usually in the nail skin folds. Skin capillaries in an area with a reduced microcirculation change in structure, and it is possible to evaluate the morphology and blood flow of the skin by microscopic studies of these capillary changes (Fagrell 1995).

More recently, dynamic capillaroscopy with sophisticated computer software programs has been used to measure microvascular dynamics, flow distribution, and permeability. The addition of fluorescent dyes to dynamic capillaroscopy enables clinicians to distinguish the microvascular from the interstitial compartments and assess transcapillary diffusion.

Certain technical aspects of these techniques make them cumbersome, including both the cost and availability of the equipment. Moreover, patients frequently need to be placed in the sitting position to ensure good blood filling of the capillaries, which makes this less physiologically dynamic.

\section{Near infrared spectroscopy (NIRS)}

Developed in the late 70s (Jobsis et al. 1977), the near infrared spectroscopy started to gain popularity, thanks to the leap in software and hardware development (Hutchinson Technology Inc., Hutchinson, MN, USA). These advancements have transformed the technology into a non-invasive beside technique that allows the measurement of microcirculatory hemoglobinoxygen availability in the investigated site. In this method, the differential absorption of infrared light at two specific wavelengths ( 680 and $800 \mathrm{~nm}$ ) by deoxyhemoglobin is used to define the hemoglobin saturation level in vessels located in the tissue volume that is illuminated by the probe (Ward et al. 2006). The dynamic response to tissue oxygen saturation $\left(\mathrm{StO}_{2}\right)$, especially the $\mathrm{StO}_{2}$ recovery slope, during a standardized vascular occlusion test (VOT) is assumed to reflect the recruitment of micro vessels in response to a local hypoxic stimulus (De Blasi et al. 2005). Even though NIRS does not provide information about the microcirculatory blood flow velocity, neither the density of the microcirculatory network of the investigated tissue, yet it provides important information about the functionality of the microcirculation, which could be of importance in clinical situation such as sepsis (Creteur et al. 2007) and could guide restoring effective intravascular volume with fluid loading in hypoperfusion and shock states (Futier $e t$ al. 2011).

\section{Orthogonal polarization spectral imaging}

The orthogonal polarization spectral (OPS) imaging was introduced in the last decade by Slaaf et al. (1987) for imaging the microcirculation using reflected light through mucus membranes and on the surface of solid organs. Being a non-invasive technique it aids in evaluating the microcirculation of submucosal tissue and organ surfaces, in both experimental and more importantly in clinical settings (Cerny et al. 2007). In OPS imaging, the tissue is illuminated with linearly polarized light and imaged through a polarizer oriented orthogonal to the plane of the illuminating light. Only depolarized photons scattered in the tissue contribute to the image (Groner et al. 1999). The optical response of OPS imaging is linear and can be used for reflection spectrophotometry over the wide range of optical density typically achieved by transmission spectrophotometry. OPS imaging produces high-contrast microvascular images from sublingual sites and the brain surface that appear as transilluminations. The technology is applied using a small optical probe, providing a convenient method for intravital microscopy on otherwise inaccessible sites and organs in the awake subject or during surgery for research and for clinical diagnostic applications. In OPS imaging, the tissue embedding the microcirculation is illuminated with polarized green light. Backscattered (and thus depolarized) light is projected onto a charge-coupled device camera after it passes an analyzer, i.e. a polarizer orthogonally-oriented with respect to the incident polarization. The light reflected by the tissue surface, which is nonpolarized, is blocked by this analyzer. By elimination of the reflected light and imaging of only the backscattered light, subsurface structures, such as the microcirculation, can be observed. The use of green light ensures sufficient optical absorption by the (de)oxyhemoglobin-containing red blood cells (RBCs) with respect to the lack of absorption by the tissue embedding the microcirculation, creating contrast (i.e. RBCs are visualized black and tissue is visualized bright, Goedhart et al. 2007). OPS imaging assesses tissue perfusion using the parameter "functional capillary density" (FCD), which is a sensitive parameter for determining the status of perfusion in a tissue and also an indirect measure of oxygen delivery. The most easily accessible site in people is the mouth, where OPS 
produces excellent images of the sublingual microcirculation. There is only weak correlation $(r=0.13)$ between the microvascular flow index calculated from paired OPS imaging in the sublingual region and in teeth (Boerma et al. 2005).

Results from several medical centers have shown that OPS observation of sublingual microcirculatory (perfusion) alterations provided more sensitive information about patient outcome from sepsis and shock than conventional clinical parameters. These microcirculatory alterations have been shown to be especially present in the smallest capillary blood vessels, making their study of particular importance. De Backer et al. (2005) demonstrated that the sublingual microcirculation in patients with severe sepsis and septic shock was markedly altered and these alterations were more severe in non-survivors (De Backer et al. 2005). The improvement of microcirculatory alterations in the first $24 \mathrm{~h}$ of resuscitation was found to be a better predictor of the outcome than changes in cardiac index, blood pressure or lactate (Sakr et al. 2004). OPS imaging was used as an objective bedside method for monitoring the effect of the treatment on microcirculatory perfusion, the passive leg elevation resulted in a rise of sublingual capillary perfusion in hypovolemic patients (Spronk and Ziekenhuizen 2005).

Despite the major contribution of OPS imaging in the field of intravital microcirculatory imaging, several shortcomings are still present (Lindert et al. 2002, Cerny et al. 2007). These include suboptimal imaging of the capillaries due to motion-induced image blurring, by movement of the OPS device, the tissue, and/or flowing RBCs. Also in larger vessels, especially during continuous flow, it is difficult to observe the granular nature of flowing blood cells due to blurring of images. This introduces difficulties in measuring blood flow velocities in these vessels.

\section{Sidestream Dark Field imaging}

Driven by the success of OPS imaging and its drawbacks, a novel modality for imaging the microcirculation was developed, Sidestream Dark Field (SDF) imaging (Ince 2005, Turek et al. 2007). In SDF imaging, illumination is provided by surrounding a central light guide by concentrically placed light emitting diodes (LEDs) to provide sidestream dark field illumination. The lens system in the core of the light guide is optically isolated from the illuminating outer ring thus preventing the microcirculatory image from contamination by tissue surface reflections. Light from the illuminating outer core of the SDF probe, which penetrates the tissue, illuminates the tissue-embedded microcirculation by scattering. The LEDs emit at a central wavelength of $530 \mathrm{~nm}$, chosen to correspond to an isosbestic point in the absorption spectra of deoxy- and oxyhemoglobin (i.e. $530 \mathrm{~nm}$ to ensure optimal optical absorption by the hemoglobin in the RBCs, independent of its oxygenation state. This leads to an image where RBCs are imaged as dark moving globules against a bright background. To improve the imaging of moving structures such as flowing RBCs, the LEDs provide pulsed illumination in synchrony with the charged coupled devices frame rate to perform intravital stroboscopy. This stroboscopic imaging, (partially) prevents smearing of moving features, such as flowing RBCs, and motion-induced blurring of capillaries due to the short illumination intervals. Goedhart et al. (2007) compared SDF and OPS images and concluded that both techniques provided similar quantitative data in terms of vessel diameters and RBCs velocity. SDF imaging provided significantly higher image quality with more detail, capillary contrast and quality, granularity of venular RBC columns, and less motion blur by the use of stroboscopic LED ring-based SDF illumination. It was then anticipated that SDF imaging will serve as a novel and improved imaging modality to contribute to the clinical assessment of the microcirculation in various clinical scenarios and allow more reliable application of computer-aided image processing and analysis software for quantification of microcirculatory alterations associated with disease and therapy. Recently, SDF imaging has emerged as the favorite technique used in clinical studies that involve evaluation of the microcirculation.

\section{Concluding remarks}

Physiological changes occurring during pregnancy involve nearly all organs in the pregnant patient, including the microcirculation, yet our understanding of these changes to this point has been concluded from the evident macrocirculatory changes.

Hemodilution peaks by 30-32 weeks of gestation. It is unclear whether or not this gives a survival advantage, but the decrease in blood viscosity may improve placental perfusion and reduce the risk of local thrombosis (Koller 1982), in the pro coagulant state of pregnancy, and provide a degree of physiological reserve 
during hemorrhage. Plasma volume may also be important for normal fetal development as pregnancies complicated by growth restriction have measurably lower mean maternal plasma volumes compared with normal fetuses (Gibson 1973). There is also evidence that obstetric outcomes and birth weight are correlated with the amount of plasma volume expansion (Pirani et al. 1973, Murphy et al. 1986).

The increased cardiac output and hemodilution is believed to play a role in the pregnant microcirculation. Our group showed a significant increase in MFI, microcirculatory flow index, in pregnant woman compared to non-pregnant woman using the SDF technology. The functional capillary density showed no significant differences between both groups (George et al. 2014).

Disturbance of the microcirculation as a result of endothelial activation/dysfunction due to the early production of cytokines (Conrad and Benyo 1997) is thought to be one of the leading etiologies in preeclampsia (Rinehart et al. 1999). Endothelial dysfunction persisted in a group of women 15-25 years following a pregnancy complicated by preeclampsia, indicating a possible link to maternal coronary disease. An enhancement in skin microvascular response was shown to exist in woman who might develop preeclampsia. These microcirculatory changes preceded the onset of clinical disease, acting as a tool that might help us in the future to identify woman whom are more prone to develop preeclampsia (Mires et al. 1998). The focus of GDM on the microcirculation is mainly directed towards the chronic changes that happen years after the pregnancy itself. These changes present as diminished vasodilatory responses as a result of endothelial dysfunction ( $\mathrm{Hu}$ et al. 1998, Hannemann et al. 2002). These changes were present 2-4 years after GDM complicated pregnancies (Hu et al. 1998).

At the molecular level, Bo et al. (2007) found that endothelial dysfunction and inflammatory markers in 82 non pregnant woman with previous GDM and 113 control women without previous GDM, 6.5 years after delivery. The markers included were C-reactive protein (CRP), interleukin-6 (IL-6), E-selectin, intercellular adhesion molecule-1 (ICAM-1), and vascular adhesion molecule-1 (VCAM-1) (Nishiyama 2007). Post GDM woman, regardless of their current metabolic status, showed significantly higher values of E-selectin and ICAM-1 than controls that was not associated with the BMI, whereas IL-6 and CRP values were higher as the BMI increased (Bo et al. 2007). They concluded that women with a GDM history, although currently free from metabolic abnormalities, appear to be at increased risk of endothelial impairment and vascular diseases in later life; and may require counseling and appropriate advice on lifestyle.

As gestational diabetes plays a role in systemic endothelial dysfunction systemically, it also seems to play a role at the vascular level in the placenta. Placentas from diabetic pregnancies show an increased incidence of vascular pathological changes. Such changes can affect the arteries and veins and are most frequently observed in stem villi of different sizes, corresponding to peripheral vessels (Daskalakis et al. 2008). These lesions affect the fetoplacental circulation (Benirschke and Kaufmann 1995).

The pregnant microcirculation remains a field that needs more light to be shed on, and might have the answers to a lot of questions that occupy obstetricians, anesthesiologists and pathologists. Whether the changes in the microcirculation in preeclampsia are a cause or a consequence remains an important question that needs to be answered. Further, it would be interesting to look into the chronic changes caused by GDM, to study the time onset at which these microcirculatory changes occur and if it affects the peripheral microcirculation.

Understanding the microcirculation during anesthesia is important to help us improve patient care and prevent complications, either for woman undergoing caesarean section or receiving epidural analgesia during labour. Anesthetists respond rapidly to hypotension induced by spinal anesthesia during caesarean sections to avoid any prolonged drops in the arterial pressure and ensure that placental fetal microcirculation is maintained preventing fetal hypoxia. But the question remains what is the best modality that ensures adequate and sufficient flow in the microcirculation. Lecouq et al. (2007) used laser-Doppler flowmetry to confirm previous data showing improved perfusion associated with spinal anesthesia. They further compared the flow between the blocked area being the lower limbs and the unblocked area, the sternum. They also looked at the counter acting effect on the perfusion when ephedrine and norepinephrine were administrated to correct the hypotension induced by spinal anesthesia. There results confirmed that spinal anesthesia resulted in an increase in skin perfusion in the blocked area and a decrease in the non-blocked area. Furthermore, they demonstrated that norepinephrine or ephedrine at doses normalizing arterial 
pressure during spinal anesthesia and causing vasoconstriction in normal volunteers do not reduce the increase in skin perfusion induced by spinal anesthesia in the blocked area. Rather, further improvement in cutaneous perfusion occurs with the restoration of MAP in this area when compared with the non-blocked area (Lecoq et al. 2010). The challenge between fluid resuscitation versus vasopressors is a controversial question, but might be more controversial knowing that there is a significant increase in blood flow in pregnant woman.

Another focus of interest is hemorrhage during caesarean sections. What is the optimal trigger for hemoglobin? The role of the capillary perfusion during hemorrhagic shock is very important. In experimental studies, it was shown that the functional capillary density (FCD) in hemorrhagic shock could be reduced up to $15-30 \%$ of baseline values in surviving animals and to $0-5 \%$ in nonsurvivals (Kerger et al. 1996). FCD can further deteriorate in experimental design of severe hemorrhagic shock with an induced mean arterial pressure of $40 \mathrm{~mm} \mathrm{Hg}$ (Kerger et al. 1999). Regardless of fresh or banked blood used, after blood transfusion, FCD increases but does not reach its initial level. However, it was shown that fresh blood transfusion is more effective in restoring functional capillaries than banked blood, particularly in the distal part of the microcirculation (Gonzalez et al. 2007).

The transition from macrocirculation to microcirculation, especially in obstetrics and gynecology has been significantly delayed. One of the main reasons could be the sensitivity of performing clinical trials in pregnant woman, with maternal and fetal welfare taking priority and limiting the possibilities of clinical research in this field. We believe that the introduction of safe, user-friendly beside technologies such as OPS and SDF would open many of the closed doors and help answer questions that have always interested researchers and clinicians trying to improve outcome in pregnancy and ensure safety during labour, especially in the field that matters most, the microcirculation.

\section{Conflict of Interest}

There is no conflict of interest.

\section{Acknowledgements}

This study was partially supported by the programme PRVOUK P37/02.

\section{References}

ABDO I, TUREK Z, PARIZKOVA R, CERNY V: Imaging of the sublingual microcirculation in the elderly patients a pilot study. Appl Cardiopulm Pathophysiol 16: 276-282, 2012.

ANDERSON TJ, UEHATA A, GERHARD MD, MEREDITH IT, KNAB S, DELAGRANGE D, LIEBERMAN EH, GANZ P, CREAGER MA, YEUNG AC: Close relation of endothelial function in the human coronary and peripheral circulations. J Am Coll Cardiol 26: 1235-1241, 1995.

AUGUST P, LINDHEIMER MD: Pathophysiology of preeclampsia. In: Hypertension. 2nd edition. JL LARAGH, BM BRENNER (eds), Raven Press, Ltd., New York, 1995, pp 2407-2426.

BENIRSCHKE K, KAUFMANN P: Maternal diseases complicating pregnancy: diabetes, tumors, preeclampsia, lupus anticoagulant. In: Pathology of the Human Placenta. 3rd ed. Springer, New York, 1995, pp 476-536.

BERGHOFER A, PISCHON T, REINHOLD T, APOVIAN CM, SHARMA AM, WILLICH SN: Obesity prevalence from a European perspective: a systematic review. BMC Public Health 26: 8-200, 2008.

BO S, VALPREDA S, MENATO G, BARDELli C, BOTTO C, GAMBINO R, RABBIA C, DURAZZO M, CASSADER M, MASSOBRIO M, PAGANO G: Should we consider gestational diabetes a vascular risk factor. Atherosclerosis 2: e72-e79, 2007.

BOERMA C, MATHURA KR, VAN DER VOORT P, SPRONK PE, INCE C: Quantifying bedside-derived imaging of microcirculatory abnormalities in septic patients: a prospective validation study. Crit Care 9: R601-R606, 2005.

BOFFA MC, VALSECCHI L, FAUSTO A, GOZIN D, VIGANO'D'ANGELO S, SAFA O, CASTIGLIONI MT, AMIRAL J, D'ANGELO A. Predictive value of plasma thrombomodulin in preeclampsia and gestational hypertension. Thromb Haemost 79: 1092-1095, 1998. 
BONTIS J, VAVILIS D, AGORASTOS T, ZOURNATZI V, KONSTANTINIDIS T, TAGOU K: Maternal plasma level of thrombomodulin is increased in mild preeclampsia. Eur J Obstet Gynecol Reprod Biol 60: 139-141, 1995.

CERNÝ V, TUREK Z, PARÍZKOVÁ R: Orthogonal polarization spectral imaging. Physiol Res 56: 141-147, 2007.

CHAPMAN AB, ABRAHAM WT, ZAMUDIO S, COFFIN C, MEROUANI A, YOUNG D, JOHNSON A, OSORIO F, GOLDBERG C, MOORE LG, DAHMS T, SCHRIER RW: Temporal relationships between hormonal and hemodynamic changes in early human pregnancy. Kidney Int 54: 2056-2063, 1998.

CLARK SL, COTTON DB, PIVARNIK JM, LEE W, HANKINS GD, BENEDETTI TJ, PHELAN JP: Position change and central hemodynamic profile during normal third-trimester pregnancy and post partum. Am J Obstet Gynecol 164: 883-887, 1998.

COMBS CA, KITZMILLER JL: Spontaneous abortion and congenital malformations in diabetes. Baillieres Clin Obstet Gynaecol 5: 315-331, 1991.

CONRAD KP, BENYO DF: Placental cytokines and the pathogenesis of preeclampsia. Am J Reprod Immunol 37: 240-249, 1997.

CONRAD KP, MILES TM, BENYO DF: Circulating levels of immunoreactive cytokines in women with preeclampsia. Am J Reprod Immunol 40: 102-111, 1998.

COTRAN RS, POBER JS: Cytokine-endothelial interactions in inflammation, immunity and vascular injury. J Am Soc Nephrol 1: 225-235, 1990.

CRETEUR J, CAROLlo T, SOlDATI G, BUCHELE G, DE BACKER D, VINCENT J: The prognostic value of muscle StO2 in septic patients. Intensive Care Med 33: 1549-1556, 2007.

DASKALAKIS G, MARINOPOULOS S, KRIELESI V, PAPAPANAGIOTOU A, PAPANTONIOU N, MESOGITIS S, ANTSAKLIS A: Placental pathology in women with gestational diabetes. Acta obstet gynecol Scand 87: 403-407, 2008.

DE BACKER D, CRETEUR J, PREISER JC, DUBOIS MJ, VINCENT JL: Microvascular blood flow is altered in patients with sepsis. Am J Respir Crit Care Med 166: 98-104, 2002.

DE BLASI RA, PALMISANI S, ALAMPI D, MERCIERI M, ROMANO R, COLLINI S, PINTO G: Microvascular dysfunction and skeletal muscle oxygenation assessed by phase-modulation near-infrared spectroscopy in patients with septic shock. Intensive Care Med 31: 1661-1668, 2005.

DE LEEUW NK, LOWENSTEIN L, TUCKER EC, DAYAL S: Correlation of red cell loss at delivery with changes in red cell mass. Am J Obstet Gynecol 100: 1092-1101, 1968.

EDVINSSON ML, ANDERSSON SE, XU CB, EDVINSSON L: Cigarette smoking leads to reduced relaxant responses of the cutaneous microcirculation. Vasc Health Risk Manag 4: 699-704, 2008.

FAGRELL B: Advances in microcirculation network evaluation: an update. Int J Microcirc 15: 34-40, 1995.

FAIN JN, NESBIT AS, SUDLOW FF, CHEEMA P, PEEPLES JM, MADAN AK: Release in vitro of adipsin, vascular cell adhesion molecule 1, angiotensin 1-converting enzyme, and soluble tumor necrosis factor receptor 2 by human omental adipose tissue as well as by the nonfat cells and adipocytes. Metabolism 56: 1583-1590, 2007.

FISHER SJ, ROBERTS JM: Defects in placentation and placental perfusion. In: Chesley's Hypertensive Disorders in Pregnancy. Second Edition, Appleton \& Lange, Stamford, CT, 1999, pp 169-199.

FUTIER E, CHRISTOPHE S, ROBIN E, PETIT A, PEREIRA B, DESBORDES J, BAZIN J, VALLET B: Use of nearinfrared spectroscopy during a vascular occlusion test to assess the microcirculatory response during fluid challenge. Crit Care 15: 214-214, 2011.

GAVIN TP, STALLINGS HW 3RD, ZWETSLOOT KA, WESTERKAMP LM, RYAN NA, MOORE RA: Lower capillary density but no difference in VEGF expression in obese vs. lean young skeletal muscle in humans. J Appl Physiol 98: 315-321, 2005.

GEORGE RB, MUNRO A, ABDO I, MCKEEN DM, LEHMANN C: An observational assessment of the sublingual microcirculation of pregnant and non-pregnant women. Int J Obstet Anesth 23: 23-28, 2014.

GERHARD M, RODDY MA, CREAGER SJ, CREAGER MA: Aging progressively impairs endothelium-dependent vasodilation in forearm resistance vessels of humans. Hypertension 27: 849-853, 1996.

GERRETSEN G, HUISJES HJ, ELEMA JD: Morphological changes of the spiral arteries in the placental bed in relation to pre-eclampsia and fetal growth retardation. Br J Obstet Gynaecol 88: 876-881, 1981. 
GIBSON HM: Plasma volume and glomerular filtration rate in pregnancy and their relation to differences in fetal growth. J Obstet Gynaecol Br Commonw 80: 1067-1074, 1973.

GOEDHART PT, KHALILZADA M, BEZEMER R, MERZA J, INCE C: Sidestream Dark Field (SDF) imaging: a novel stroboscopic LED ring-based imaging modality for clinical assessment of the microcirculation. Opt Express 15: 15101-15114, 2007.

GONZALEZ AM, YAZICI I, KUSZA K, SIEMIONOW M: Effects of fresh versus banked blood transfusions on microcirculatory hemodynamics and tissue oxygenation in the rat cremaster model. Surgery 141: 630-639, 2007.

GRONER W, WINKELMAN JW, HARRIS AG, INCE C, BOUMA GJ, MESSMER K, NADEAU RG: Orthogonal polarization spectral imaging: a new method for study of the microcirculation. Nat Med 5: 1209-1212, 1999.

HANNEMANN MM, LIDDELL WG, SHORE AC, CLARK PM, TOOKE JE: Vascular function in women with previous gestational diabetes mellitus. J Vasc Res 39: 311-319, 2002.

HARSTAD TW, MASON RA, COX SM: Serum erythropoietin quantitation in pregnancy using an enzyme-linked immunoassay. Am J Perinatol 9: 233-235, 2001.

HASHIMOTO M, AKISHITA M, ETO M, KOZAKI K, AKO J, SUGIMOTO N: The impairment of flow-mediated vasodilatation in obese men with visceral fat accumulation. Int J Obes Relat Metab Disord 22: 477-484, 1998.

HESLEHURST N, ELLS LJ, SIMPSON H, BATTERHAM A, SUMMERBELL CD: Trends in maternal obesity incidence rates, demographic predictors, and health inequalities in 36,821 women over a 15 -year period. BJOG 114: 187-194, 2007.

HU J, NORMAN M, WALLENSTEEN M, GENNSER G: Increased large arterial stiffness and impaired acetylcholine induced skin vasodilatation in women with previous gestational diabetes mellitus. Br J Obstet Gynaecol 105: 1279-1287, 1998.

HUONKER M, HALLE M, KEUL J: Structural and functional adaptations of the cardiovascular system by training. Int J Sports Med 17: 164-172, 1996.

INCE C: The microcirculation is the motor of sepsis. Crit Care 9 (Suppl 4): S13-S19, 2005.

JOVANOVIC L, PETTITT DJ: Gestational diabetes mellitus. JAMA 286: 2516-2518, 2001.

JUNG F, WAPPLER M, NÜTTGENS HP, KIESEWETTER H, WOLF S, MÜLLER G: Method of video capillary microscopy: determination of geometric and dynamic measuring parameters (in German). Biomed Tech (Berl) 32: 204-213, 1987.

KERGER H, SALTZMAN DJ, MENGER MD, MESSMER K, INTAGLIETTA M: Systemic and subcutaneous microvascular Po2 dissociation during 4-h hemorrhagic shock in conscious hamsters. Am J Physiol 270: H827H836, 1996.

KERGER H, WASCHKE KF, ACKERN KV, TSAI AG, INTAGLIETTA M: Systemic and microcirculatory effects of autologous whole blood resuscitation in severe hemorrhagic shock. Am J Physiol 276: H2035-H2043, 1999.

KHAN F, BELCH JJ, MACLEOD M, MIRES G: Changes in endothelial function precede the clinical disease in women in whom preeclampsia develops. Hypertension 46: 1123-1128, 2005.

KOLLER O: The clinical significance of hemodilution during pregnancy. Obstet Gynecol Surv 37: 649-652, 1982.

KVERNMO HD, STEFANOVSKA A, KIRKEBOEN KA, OSTERUD B, KVERNEBO K: Enhanced endotheliumdependent vasodilatation in human skin vasculatureinduced by physical conditioning. Eur J Appl Physiol Occup Physiol 79: 30-36, 1998.

LECOQ JP, BRICHANT JF, LAMY ML, JORIS JL: Norepinephrine and ephedrine do not counteract the increase in cutaneous microcirculation induced by spinal anaesthesia. Br J Anaesth 105: 214-219, 2010.

LINDERT J, WERNER J, REDLIN M, KUPPE H, HABAZETTL H, PRIES AR: OPS imaging of human microcirculation: a short technical report. J Vasc Res 39: 368-372, 2002.

MASTROGIANNIS DS, O'BRIEN WF, KRAMMER J, BENOIT R: Potential role of endothelin-1 in normal and hypertensive pregnancies. Am J Obstet Gynecol 165: 1711-1716, 1991.

METZGER BE: Summary and recommendations of the Third International Workshop: Conference on Gestational Diabetes Mellitus. Diabetes 40: 197-201, 1991.

MIDTTUN M, SEJRSEN P, PAASKE WP: Blood flow rate during orthostatic pressure changes in the pulp skin of the first toe. Eur J Vasc Endovasc Surg 13: 278-284, 1997. 
MIDTTUN M, SEJRSEN P, PAASKE WP: Peripheral blood flow rates and microvascular responses to orthostatic pressure changes in claudicants before and after revascularisation. Eur J Vasc Endovasc Surg 17: 225-229, 1999.

MIRES GJ, WILLIAMS FL, LESLIE J, HOWIE PW: Assessment of uterine arterial notching as a screening test for adverse pregnancy outcome. Am J Obstet Gynecol 179: 1317-1323, 1998.

MORON AF, DE ALMEIDA PA, CAMANO L: Pregnancy in women 40 years of age and over: analysis of variables in the mothers and newborn infants. Rev Paul Med 107: 203-211, 1989.

MURPHY JF, O'RIORDAN J, NEWCOMBE RG, COLES EC, PEARSON JF: Relation of haemoglobin levels in first and second trimesters to outcome of pregnancy. Lancet 1: 992-995, 1986.

NISHIYAMA T: Changes in percutaneous oxygen tension induced by spinal anesthesia. J Anesth 21: 317-319, 2007.

OHLMANN P, JUNG F, MROWIETZ C, ALT T, ALT S, SCHMIDT W: Peripheral microcirculation during pregnancy and in women with pregnancy induced hypertension. Clin Hemorheol Microcirc 24: 183-191, 2001.

PIJNENBORG R, ANTHONY J, DAVEY DA, REES A, TILTMAN A, VERCRUYSSE L, VAN ASSCHE A: Placental bed spiral arteries in the hypertensive disorders of pregnancy. Br J Obstet Gynaecol 98: 648-655, 1991.

PIRANI BB, CAMPBELL DM, MACGILLIVRAY I: Plasma volume in normal first pregnancy. J Obstet Gynaecol Br Commonw 80: 884-887, 1973.

RAMSAY JE, STEWART F, GREER IA: Microvascular dysfunction: a link between pre-eclampsia and maternal coronary heart disease. BJOG 110: 1029-1031, 2003.

RANTA V, VIINIKKA L, HALMESMAKI E, YLIKORKALA O: Nitric oxide production with preeclampsia. Obstet Gynecol 93: 442-445, 1999.

RINEHART BK, TERRONE DA, LAGOO-DEENADAYALAN S, BARBER WH, HALE E, MARTIN JN, BENNETT WA: Expression of the placental cytokines tumor necrosis factor alpha, interleukin-1 beta, and interleukin-10 is increased in preeclampsia. Am J Obstet Gynecol 181: 915-920, 1999.

ROBERTS JM, TAYLOR RN, GOLDFIEN A: Clinical and biochemical evidence of endothelial cell dysfunction in the pregnancy syndrome preeclampsia. Am J Hypertens 4: 700-708, 1991.

SAAD AR, STEPHENS DP, BENNETT LA, CHARKOUDIAN N, KOSIBA WA, JOHNSON JM: Influence of isometric exercise on blood flow and sweating in glabrous and nonglabrous human skin. J Appl Physiol 91: 2487-2492, 2001.

SAKR Y, DUBOIS MJ, DE BACKER D, CRETEUR J, VINCENT JL: Persistent microvasculatory alterations are associated with organ failure and death in patients with septic shock. Crit Care Med 32: 1825-1831, 2004.

SCARDINA GA: The effect of cigar smoking on the lingual microcirculation. Odontology 93: 41-45, 2005.

SHAAMASH AH, ELSNOSY ED, MAKHLOUF AM, ZAKHARI MM, IBRAHIM OA, EL-DIEN HM: Maternal and fetal serum nitric oxide concentration in normal pregnancy, pre-eclampsia and eclampsia. Int $J$ Gynaecol Obstet 68: 207-214, 2000.

SLAAF DW, TANGELDER GJ, RENEMAN RS, JAGER K, BOLLINGER A: A versatile incident illuminator for intravital microscopy. Int J Microcirc Clin Exp 6: 391-397, 1987.

SIAFAKA A, ANGELOPOULOS E, KRITIKOS K: Acute effects of smoking on skeletal muscle microcirculation monitored by near-infrared spectroscopy. CHEST 131: 1479-1485, 2007.

SPRONK P, ZIEKENHUIZEN G: The response of the microcirculation to volume. In: Abstracts of the 2nd International Symposium on Microcirculation and Mitochondrial Dysfunction in Intensive Care Medicine. Amsterdam, 2005, p. 29.

STEINBERG HO, CHAKER H, LEAMING R, JOHNSON A, BRECHTEL G, BARON AD: Obesity/insulin resistance is associated with endothelial dysfunction. Implications for the syndrome of insulin resistance. J Clin Invest 97 : 2601-2610, 1996.

SUD SS, GUPTA I, DHALIWAL LK, KAUR B, GANGULY NK: Serial plasma fibronectin levels in preeclamptic and normotensive women. Int J Gynaecol Obstet 66: 123-128, 1999.

TADDEI S, VIRDIS A, MATTEI P, GHIADONI L, GENNARI A, FASOLO CB, SUDANO I, SALVETTI A: Aging and endothelial function in normotensive subjects and patients with essential hypertension. Hypertension 91: 1981-1987, 1995. 
TAO J, JIN YF, YANG Z, WANG LC, GAO XR, LUI L, MA H: Reduced arterial elasticity is associated with endothelial dysfunction in persons of advancing age: comparative study of noninvasive pulse wave analysis and laser Doppler blood flow measurement. Am J Hypertens 17: 654-659, 2004.

TUREK Z, CERNÝ V, PARÍZKOVÁ R: Noninvasive in vivo assessment of the skeletal muscle and small intestine serous surface microcirculation in rat: sidestream dark-field (SDF) imaging. Physiol Res 57: 365-371, 2008.

VAN GUILDER GP, STAUFFER BL, GREINER JJ, DESOUZA CA: Impaired endothelium-dependent vasodilation in overweight and obese adult humans is not limited to muscarinic receptor agonists. Am J Physiol Heart Circ Physiol 294: H1685-H1692, 2008.

VERMA S, BUCHANAN MR, ANDERSON TJ: Endothelial function testing as a biomarker of vascular disease. Circulation 108: 2054-2059, 2003.

VILLELA NR, AGUIAR LG, BAHIA L, BOTTINO D, BOUSKELA E: Does endothelial dysfunction correlate better with waist-to-hip ratio than with body mass index or waist circumference among obese patients? Clinics 61: 53-58, 2006.

WALSH SW, BEHR MJ, ALLEN NH: Placental prostacyclin production in normal and toxemic pregnancies. $A m J$ Obstet Gynecol 151: 110-115, 1985.

WANG Y, WALSH SW: TNF alpha concentrations and mRNA expression are increased in preeclamptic placentas. J Reprod Immunol 32: 157-169, 1996.

WARD KR, IVATURY R, BARBEE RW, TERNER J, PITTMAN R, FILHO IP, SPIESS B: Near infrared spectroscopy for evaluation of the trauma patient: a technology review. Resuscitation 68: 27-44, 2006. 